\title{
DETERMINAN PERMINTAAN KARET INDONESIA
}

\author{
Muhammad Hartana I. Putra \\ UIN Syarif Hidayatullah Jakarta \\ hartana@uinjkt.ac.id
}

\begin{abstract}
The aim of this research is to analyze the factors that determinant the rubber demand by Unites States of America. The analysis method of this research is Partial Adjustment Model. Demand of Indonesia rubber by United States of America at research time line of 1995.1 up to 2007.4, simply only influenced by the price of rubber in international market. As for international price influence of rubber to demand of rubber by United States of America from Indonesian is significant and negativity. Whereas other independent variable is federal exchange rate and US's GDP doesn't have an effect on to demand of rubber by United States of America.
\end{abstract}

Keywords: Demand; Rubber; Partial Adjustment Model

\begin{abstract}
Abstrak
Tujuan dari penelitian ini ialah untuk menganalisis faktor-faktor yang mempengaruhi permintaan karet oleh Amerika Serikat. Metode analisis yang dipergunakan ialah model penyesuaian parsial. Tahun penelitian terkait permintaan karet Indonesia oleh Amerika Serikat ini menggunakan data dari triwulan pertama tahun 1995 sampai dengan triwulan keempat tahun 2007, hal yang sederhana yang dipengaruhi ialah harga karet pada pasar internasional. Sebagaimana dengan harga karet internasional, permintaan karet oleh Amerika Serikat terhadap Indonesia adalah signifikan dan negatif. Sedangkan variabel independen lain seperti nilai tukar dan pendapatan domestik bruto Amerika Serikat tidak memiliki pengaruh terhadap permintaan karet Indonesia oleh Amerika Serikat.
\end{abstract}

Kata Kunci: Permintaan; Karet; Model Penyesuaian Parsial 


\section{PENDAHULUAN}

Salah satu komoditi non-migas yang diekspor negara Indonesia adalah karet. Penelitian ini akan menganalisis ekspor komoditi karet karena negara Indonesia merupakan salah satu negara penghasil karet terbesar di dunia setelah Malaysia pada urutan teratas. Apalagi saat ini pemerintah sedang bersemangat membuat peraturan-peraturan dan kebijaksanaan yang bertujuan untuk menunjang dan menggalakkan ekspor non-migas. Nilai ekspor karet Indonesia rata-rata mengalami peningkatan hampir pada setiap tahunnya. Peningkatan terbesar terjadi pada tahun 2006 yaitu sebesar 5.528.000 Ribu US \$, dari tahun 2005 yang hanya 793.000 Ribu US \$. Walaupun pada tahun 2000-2001 terjadi penurunan yang cukup signifikan, namun nilai ekspor karet Indonesia menunjukkan kenaikan kembali pada tahun 2002.

Ekspor karet Indonesia banyak dinikmati negara lain, terutama negaranegara maju. Adapun negara pengimpor karet dari Indonesia yang paling utama sampai saat ini masih diduduki Amerika Serikat, disusul Singapura kemudian Jepang di urutan ke tiga. Dipilihnya Amerika Serikat sebagai negara tujuan ekspor karet Indonesia, karena Amerika serikat merupakan tujuan ekspor non-migas Indonesia kedua setelah Jepang. Tahun 1987 ekspor nonmigas ke Amerika Serikat sebesar 1,6 milyar Dollar Amerika Serikat dan tahun 2000 meningkat menjadi 8,1 milyar Dollar. Namun peranannya terhadap ekspor non-migas nasional hanya berkisar 14\%-16\%. Tetapi Amerika Serikat memiliki potensi pasar yang amat besar yang dilihat dari GDP-nya yang mencapai 13,7 trilyun Dollar Amerika Serikat tahun 2007.

Oleh karena itu, perekonomian Amerika Serikat dinilai cukup dominan menentukan ekspor komoditi karet Indonesia. Peranan ekspor karet Indonesia dan bahkan untuk ekspor non-migas keseluruhan terhadap total impor Amerika Serikat, perananya amat kecil. Meskipun demikian, ekspor non-migas Indonesia ke Amerika Serikat cukup menentukan bagi Indonesia. Secara teoritis, kecilnya market share ekspor karet Indonesia ke Amerika Serikat menjadikan posisi Indonesia seperti pemain dalam pasar persaingan sempurna, dimana menempatkan Indonesia pada posisi marjinal dalam negosiasi dagang dengan Amerika Serikat. 
Menyadari akan pentingnya pasar global dan mobilitas produksi modal dan jasa yang semakin cepat, maka sebagai penganut sistem perekonomian terbuka lalu lintas perdagangan internasional dirasakan perlu mendapat perhatian serius agar ada tambahan bagi pemupukan devisa. Tidak selamanya Indonesia dapat bergantung pada hasil migas, mengingat migas merupakan hasil alam yang tidak dapat diperbaharui. Sudah seharusnya Indonesia memperhatikan sektor non-migas. Karena hasil non-migas selain penggerak pertumbuhan ekonomi nasional juga sebagai sumber penerimaan devisa. Indonesia merupakan salah satu negara peng-ekspor karet terbesar dengan negara tujuan ekspor Amerika Serikat. Meskipun komoditi karet hanya bagian kecil dari ekspor non-migas secara keseluruhan, tetapi tetap memberikan nilai positif dalam penerimaan devisa sektor non-migas Indonesia.

\section{METODE}

Data yang digunakan dalam penelitian ini adalah data sekunder, data ini diperoleh dari berbagai sumber antara lain dari perpustakaan terkait dan literatur yang ada hubungannya dengan masalah yang akan dibahas. Data yang digunakan merupakan data runtun waktu (time series) yaitu periode 1995.1-2007.4.

Data yang digunakan merupakan data sekunder, data tersebut meliputi: (1) Ekspor riil didefinisikan sebagai kuantias permintaan karet Indonesia oleh Amerika Serikat; (2) Harga karet internasional, yaitu harga karet yang berlaku di pasar internasional yang dalam penelitian ini adalah pasar Amerika Serikat dalam satuan Dollar Amerika Serikat dideflasikan terhadap inflasi. Inflasi diukur berdasarkan indeks harga konsumen Amerika Serikat. Harga karet internasional di suatu negara juga merupakan rasio harga karet internasional terhadap harga karet dalam negeri; (3) Nilai tukar dolar Amerika terhadap rupiah, dalam penelitian ini yang digunakan adalah nilai tukar nominal yang merupakan harga relatif dari mata uang kedua negara atau juga dapat dikatakan sebagai tingkat harga yang disepakati penduduk kedua negara untuk saling melakukan perdagangan; (4) GDP riil Amerika Serikat $\left(X_{3}\right)$, yang digunakan pada penelitian ini yaitu dengan tahun dasar 
1990. GDP riil merupakan ukuran untuk menghitung nilai total produksi seluruh barang dan jasa yang penilaiannya didasarkan pada harga konstan.

Estimasi dengan metode PAM ( Partial Adjustment Model) ini nantinya ada dua bagian utama, yaitu estimasi model untuk periode jangka pendek dan estimasi model untuk periode jangka panjang. Dengan mempertimbangkan kajian teoritis dan empiris, serta kondisi riil perekonomian nasional, model dalam penelitian ini diformulasikan sebagai berikut :

$$
\mathrm{Eks}_{\mathrm{t}}=\mathrm{C}_{0}+\mathrm{C}_{1} \mathrm{HI}+\mathrm{C}_{2} \text { Kurs }_{\mathrm{t}}+\mathrm{C}_{3} \text { GDPAS }_{\mathrm{t}}+\mathrm{C}_{4} \mathrm{Eks}_{\mathrm{t}-1}+\mathrm{e}
$$

Koefisien $\mathrm{c}_{0}, \mathrm{c}_{1}, \mathrm{c}_{2}, \mathrm{C}_{3}$ dan $\mathrm{c}_{4}$ adalah menunjukkan nilai koefisien jangka pendek dari variabel $\mathrm{HI}$, Kurs, GDPAS dan $\mathrm{Eks}_{\mathrm{t}-1}$. Lebih lanjut syarat utama dari estimasi dengan model PAM adalah koefisien variabel kelambanan nilainya adalah terletak antara $0<\beta_{4}<1$ dan harus signifikan secara statistik, apabila syarat tersebut terpenuhi maka model PAM dapat dipergunakan untuk mengestimasi model yang ada (Insukindro dan Aliman, 2001). Menurut Insukindro dan Aliman (2001), untuk menghitung nilai koefisien jangka panjang dari variabel bebas dengan menggunakan model PAM dapat dilakukan dengan menggunakan rumus sebagai berikut:

$$
\begin{aligned}
& \mathrm{HI}=\mathrm{c}_{1} /\left(1-\mathrm{c}_{4}\right) \\
& \text { Kurs }=\mathrm{c}_{2} /\left(1-\mathrm{c}_{4}\right) \\
& \text { GDPAS }=\mathrm{c}_{3} /\left(1-\mathrm{c}_{4}\right)
\end{aligned}
$$

Dimana:

Eks $_{\mathrm{t}}=$ kuantitas ekspor karet dari Indonesia ke Amerika Serikat waktu $\mathrm{t}$

$\mathrm{HI}_{\mathrm{t}} \quad=$ harga karet di pasar internasional pada waktu $\mathrm{t}$

Kurs $_{\mathrm{t}} \quad=$ nilai tukar dolar AS terhadap rupiah pada waktu $\mathrm{t}$

GDPAS = GDP Amerika Serikat pada waktu $\mathrm{t}$

$\mathrm{EkS}_{\mathrm{t}-1}=$ kuantitas ekspor karet dari Indonesia ke Amerika Serikat waktu $\mathrm{t}-1$

\section{HASIL DAN PEMBAHASAN}

Untuk melihat apakah ada hubungan antara residual time series (antar waktu) pada model OLS yang digunakan sehingga hasil estimasi menjadi bias maka perlu diidentifikasikan kemungkinan terjadinya autokorelasi pada model 
empiris yang digunakan. Identifikasi tersebut dapat dilakukan dengan menggunakan uji Breusch-Godfrey Serial Correlation LM Test.

\section{Tabel 1. Uji Autokorelasi}

Breusch-Godfrey Serial Correlation LM Test:

\begin{tabular}{llll}
\hline \hline F-statistic & 0.304866 & Prob. $\mathrm{F}(2,43)$ & 0.738803 \\
Obs*R-squared & 0.699077 & Prob. Chi-Square $(2)$ & 0.705013 \\
& $=$
\end{tabular}

Nilai Obs*R-squared $(2,426827)$ lebih kecil dari nilai $X^{2}$ tabel $(5,9915)$ pada derajad kesalahan $(\alpha)=5 \%$; atau dapat juga dilihat dari probablity untuk Obs* R-squared, ini nilainya adalah 0,297181, yang mana nilai tersebut adalah lebih besar dari derajad kesalahan $(\alpha)=5 \%(0,05)$, maka berarti tidak ada permasalahan autokorelasi.

Untuk menguji bahwa varian (error term) dari data observasi dalam penelitian ini sama (homogen) untuk semua variabel terikat dengan variabel bebas sehingga hasil estimasi tidak bias, maka perlu di identifikasi melalui uji heteroskedastisitas. Untuk membuktikan apakah data observasi dalam penelitian ini terbebas dari pengaruh heteroskedastisitas atau memenuhi asumsi-asumsi homoskedastik, maka ditempuh melalui Arch Test.

Tabel 2. Uji Heteroskedastisitas (cross term)

White Heteroskedasticity Test:

\begin{tabular}{llll}
\hline \hline F-statistic & 2.336963 & Prob. F(14,35) & 0.020971 \\
Obs*R-squared & 24.15734 & Prob. Chi-Square(14) & 0.043857 \\
\hline
\end{tabular}

Nilai probablity untuk Obs*R-squared (cross term), adapun nilainya adalah $(0.043857)$ adalah lebih kecil dari derajad kesalahan $(\alpha)=5 \%(0,05)$, artinya uji heteroskedastisitasnya signifikan oleh karena itu pada metode ini ada permasalahan heteroskedastisitas.

Nilai probablity untuk F-statitiknya (0.697371) ternyata lebih besar dari derajad kesalahan $(\alpha)=5 \%(0,05)$, artinya uji ketidak linieran ini tidak signifikan, oleh karena itu tidak ada permasalahan ketidaklinieran atau model ini adalah linier. 


\section{Tabel 3. Uji Linieritas}

Ramsey RESET Test:

\begin{tabular}{llll}
\hline \hline F-statistic & 0.153215 & Prob. F(1,44) & 0.697371 \\
Log likelihood ratio & 0.173806 & Prob. Chi-Square(1) & 0.676752 \\
\hline
\end{tabular}

Nilai probablity-nya $(0,000000)$ ternyata lebih kecil dari derajad kesalahan $(\alpha)=5 \%(0,05)$, artinya uji ketidaknormalan ini adalah signifikan, oleh karena itu dapat dinyatakan di sini bahwa pada model ini ada permasalahan normalitas. Ada dua uji yang tidak lolos yaitu uji heteroskedastisitas yang cross tern dan uji normalitas, akan tetapi hal ini tidak akan menjadi masalah apabila nantinya hasil olah data dengan PAM dari model yang ada ternyata bagus (sesuai dengan ketentuan yang ada).

Rumus yang digunakan dalam model penelitian dengan metode PAM (Partial Adjustment Modell ) ini, adalah sebagai berikut:

$$
\mathrm{Eks}_{\mathrm{t}}=\mathrm{C}_{0}+\mathrm{C}_{1} \mathrm{HI}+\mathrm{C}_{2} \mathrm{Kurs}_{\mathrm{t}}+\mathrm{C}_{3} \text { GDPAS }_{\mathrm{t}}+\mathrm{c}_{4} \mathrm{Eks}_{\mathrm{t}-1}+\mathrm{e}
$$

Estimasi hubungan antara variabel-variabel yang mempengaruhi inflasi di Indonesia dilakukan melalui pendekatan model PAM ( Partial Adjustment Modell ) sebagaimana yang ditampilkan pada tabel 4 .

Syarat utama dari estimasi dengan model PAM adalah koefisien variabel kelambanan nilainya adalah terletak antara $0<\beta_{4}<1$ dan harus signifikan secara statistik, apabila syarat tersebut terpenuhi maka model PAM dapat dipergunakan untuk mengestimasi model yang ada. Dari hasil olah data tersebut di atas dapat diketahui bahwa nilai koefisien variabel bebas DLEKS1 adalah 0,324742 dan signifikan secara statistik karena nilai probabilitas signifikansinya adalah $=0,0166$; nilai ini lebih kecil dari derajad kesalahan $(\alpha)=5 \%(0,05)$. Dengan demikian dapat dikatakan bahwa model PAM ini sukses dan dapat dipergunakan untuk mengestimasi model permintaan karet Indonesia oleh Amerika Serikat, selama periode penelitian. Nilai koefisien penyesuaian (coefficient of adjustment) yaitu $\left(1-\beta_{4}\right)=1-0,324742=$ 0,675258, yang berarti bahwa 67,5258 \% ketidaksesuaian antara laju permintaan karet Indonesia oleh Amerika Serikat yang aktual dengan yang diinginkan akan dieliminasi atau dihilangkan dalam satu triwulan. 
Tabel 4. Hasil Olah Data Dengan Metode PAM

\begin{tabular}{|c|c|c|c|c|}
\hline $\begin{array}{l}\text { Dependent Variable: } \\
\text { Method: Least Squar } \\
\text { Sample (adjusted): } 1 \\
\text { Included observation }\end{array}$ & $\begin{array}{l}\text { ESS } \\
\text { Q3 2007Q4 } \\
0 \text { after adjus }\end{array}$ & nents & & \\
\hline Variable & Coefficient & Std. Error & t-Statistic & Prob. \\
\hline $\mathrm{C}$ & -0.002734 & 0.011481 & -0.238099 & 0.8129 \\
\hline DLHI & -0.880238 & 0.327053 & -2.691419 & 0.0100 \\
\hline DLKURS & -0.034530 & 0.034292 & -1.006953 & 0.3193 \\
\hline DLGDPAS & 0.412676 & 1.051824 & 0.392343 & 0.6967 \\
\hline DLEKS1 & 0.324742 & 0.130509 & 2.488267 & 0.0166 \\
\hline R-squared & 0.324636 & Mean depe & dent var & 0.009773 \\
\hline Adjusted R-squared & 0.264604 & S.D. deper & lent var & 0.041957 \\
\hline S.E. of regression & 0.035980 & Akaike info & criterion & -3.717061 \\
\hline Sum squared resid & 0.058256 & Schwarz c & erion & -3.525859 \\
\hline Log likelihood & 97.92653 & F-statistic & & 5.407693 \\
\hline Durbin-Watson stat & 2.123832 & Prob(F-sta & stic) & 0.001213 \\
\hline
\end{tabular}

Nilai $R^{2}$ yang diperoleh dari hasil estimasi sebesar 0,324636 . Hal ini berarti bahwa 32,4636 \% dari variasi permintaan karet Indonesia oleh Amerika Serikat mampu dijelaskan oleh variabel bebas dengan model PAM. Nilai $R^{2}$ yang rendah ini tidak layak untuk diperbandingkan dengan pada $R^{2}$ yang tinggi pada model yang tanpa pengenaan diference dan logaritma pada variabelnya. Nilai $R^{2}$ pada variabel model yang dikenai diference dan logaritma pasti akan rendah. Berkaitan dengan nilai probabilitas F-Statistik yang signifikan secara statistik yaitu sebesar 0,001213; menunjukkan bahwa variabel-variabel bebas dalam pengamatan ini secara bersama-sama mampu mempengaruhi variabel tak bebas.

Berdasarkan hasil estimasi, model PAM yang ada. variabel yang signifikan secara statistik hanyalah harga internasional $(\mathrm{DLHI})$, koefisien $\mathrm{c}_{1}=$ $-0,880238$ dan ini signifikan secara statistik karena nilai probabilitas signifikansinya $(0,0100)$ ini lebih kecil dari $\alpha=5 \%(0,05)$. Ini berarti dalam jangka pendek apabila laju DLHI meningkat $1 \%$ maka laju permintaan karet Indonesia oleh Amerika Serikat akan turun sebesar 88,0238 \%. Untuk variabel DLKurs dan DLGDPAS dalam jangka pendek, tidak berpengaruh terhadap permintaan karet Indonesia oleh Amerika Serikat. Koefisien jangka panjang DLHI adalah $c_{1} /\left(1-c_{4}\right)=-0,880238 /(1-0,324742)=-1,303558$, artinya 
dalam jangka panjang apabila laju DLHI meningkat sebesar $1 \%$ maka laju permintaan karet Indonesia oleh Amerika Serikat akan turun sebesar $130,3558 \%$. Untuk variabel Kurs dan GDPAS dalam jangka panjang, tidak berpengaruh terhadap permintaan karet Indonesia oleh Amerika Serikat.

Kondisi perekonomian suatu negara dapat diamati dengan melihat perubahan indikator-indikator ekonomi makro. Perubahan tersebut berkaitan dengan implementasi kebijakan ekonomi makro baik dari sisi moneter maupun fiskal. Ekspor merupakan salah satu indikator yang pengelolaannya terus difasilitasi oleh pemerintah agar terus meningkat, guna menciptakan pertumbuhan ekonomi, peningkatan output riil dan perluasan kesempatan kerja. Hasil penelitian ini menemukan kenyataan bahwa dalam jangka pendek variabel laju Harga Internasional $(\mathrm{HI})$ memberi kontribusi negatif dan signifikan terhadap laju permintaan karet Indonesia oleh Amerika Serikat. Ini memang agak bertentangan dengan teori, karena kalau sesuai teori harusnya berpengaruh positif, namun dapat dijelaskan sebagai berikut, pengaruh negatif harga internasional terhadap ekspor karet ini terjadi karena para eksportir indonesia kalah cepat dalam mendapatkan informasi tentang harga karet di pasar internasional dibandingkan para importir Amerika Serikat, para Importir di Amerika Serikat begitu mereka tahu bahwa harga internasional karet naik mereka kemudian menunda permintaan impor karet dari Indonesia. Hal inilah yang mengakibatkan pengaruh negatif dari harga internasional karet terhadap ekspor karet Indonesia. Analisis jangka pendek ini bermanfaat bagi pengambilan kebijakan guna meningkatkan Ekspor karet Indonesia, misal dengan memberi pelatihan internet bagi para eksportir karet Indonesia, agar mereka cepat mengetahui apabila harga karet internasional naik; atau dapat juga dengan cara kontrak jangka panjang dalam ekspor karet ke Amerika Serikat ini, agar tidak begitu terpengaruh apabila harga karet internasional naik atau turun.

Hasil penelitian ini menemukan kenyataan bahwa dalam jangka panjang variabel laju harga internasional $(\mathrm{HI})$ memberi kontribusi negatif dan signifikan terhadap laju permintaan karet Indonesia oleh Amerika Serikat. Ini memang agak bertentangan dengan teori, karena kalau sesuai teori harusnya berpengaruh positif, namun dapat dijelaskan sebagai berikut, dalam jangka 
panjang pengaruh negatif harga internasional terhadap ekspor karet ini terjadi karena para eksportir indonesia kalah cepat dalam mendapatkan informasi tentang harga karet di pasar internasional dibandingkan para importir Amerika Serikat, para Importir di Amerika Serikat begitu mereka tahu bahwa harga internasional karet naik mereka kemudian menunda permintaan impor karet dari Indonesia. Hal inilah yang mengakibatkan pengaruh negatif dari harga internasional karet terhadap ekspor karet Indonesia. Hasil ini akan menambah keragaman hasil penelitian tentang analisis permintaan karet Indonesia oleh Amerika Serikat.

\section{SIMPULAN}

Dalam jangka pendek maupun jangka panjang variabel laju harga internasional ( $\mathrm{HI}$ ) berpengaruh negatif dan signifikan terhadap laju permintaan karet Indonesia oleh Amerika Serikat. Nilai koefisien variabel bebas Eks adalah bernilai 0,324742 dan signifikan secara statistik. Dengan demikian dapat dikatakan bahwa model PAM ini sukses dan dapat dipergunakan untuk mengestimasi model inflasi di Indonesia selama periode penelitian. Dalam jangka pendek dan jangka panjang variabel laju Kurs dan laju GDPAS tidak berpengaruh terhadap laju permintaan karet Indonesia oleh Amerika Serikat. Secara bersama-sama laju harga internasional, laju kurs dan laju GDPAS mampu mempengaruhi laju permintaan karet Indonesia oleh Amerika Serikat.

\section{PUSTAKA ACUAN}

Asafu, John, Adjaye. 1999. Exchange Rate Variability and Export Growth in Fiji. Australia: Asia Pacific Press.

Boediono. 1983. Ekonomi Internasional. Yogyakarta: BPFE UGM.

Engle, R.F \& Granger, C.W.J. 1991. Long Run Economic RelationshipReadings in Cointegration. New York: Oxford University Press.

Fountas, Aristotelous. 2000. Does The Exchange Rate Regime Affect Export Volumes? Evidence From Bilateral Exports in The US-UK Trade: 1990-1998. Working Paper No. 43, Departement of Economics National University of Ireland, Galway. 
Insukindro. 1999. Pemilihan Model Ekonomi Empirik Dengan Pendekatan Koreksi Kesalahan. Jurnal Ekonomi dan Bisnis Indonesia, Vol. 14, No. 1.

Insukindro dan Aliman. 2001. Ekonometrika Terapan: Analisis Runtun Waktu. Yogyakarta: BPFE-UGM.

Muqorobin. 1989. Analisis Jangka Pendek dan Jangka Panjang Terhadap Beberapa Variabel Yang Mempengaruhi Permintaan Impor Produk Rekayasa Di Indonesia. Skripsi tidak dipublikasikan. Yogyakarta: Universitas Gadjah Mada.

Soepono, Prasetyo. 2001. Teori Pertumbuhan Berbasis Ekonomi (Ekspor). Posisi dan Sumbangannya Bagi Perbendaharaan Alat-Alat Analisis Regional. Jurnal Ekonomi dan Bisnis Indonesia Vol. 16 No.1.

Udjianto, Didiet W. 2003. Kajian Ekonomi Ekspor Karet Alam Indonesia, Tinjauan Nilai Tukar Rupiah Tahun 1984- 1999. Yogyakarta: Buletin Ekonomi Volume 5. 